\title{
A suggestion for simplifying the theory of asset prices
}

\author{
Riccardo Cesari \\ Università di Bologna, Dip. Matemates, viale Filopanti, 5 \\ 40126 Bologna, Italy \\ E-mail: rcesari@economia.unibo.it \\ Carlo D'Adda \\ Università di Bologna, Dip. Scienze economiche, strada Maggiore, 45 \\ 40125 Bologna, Italy \\ E-mail: dadda@spbo.unibo.it
}

\begin{abstract}
Using an ordinal approach to utility, in the spirit of Hicks $(1962,1967 \mathrm{a})$, it is possible to greatly simplify the theory of asset prices. The basic assumption is to summarize any probability distribution into its moments so that preferences over distributions can be mapped into preferences over vectors of moments. This implies that assets, like Lancaster's (1966) consumption goods, are bundles of characteristics and can be directly priced, at the margin, in terms of the market portfolio. Expected utility is not required and both St.Petersburg and Allais paradoxes may be easily solved.
\end{abstract}

JEL classification: G12, G13

Keywords: asset pricing, utility, CAPM, St. Petersburg paradox, Allais paradox

Paper presented to “John Hicks: One Hundredth Anniversary Workshop”, Bologna, October, $10^{\text {th }}-11^{\text {th }}, 2004$ 


\section{Introduction}

Opening his essay "A suggestion for simplifying the theory of money”, John Hicks (1935) described his uneasiness as a non-monetary economist trying to deal with a subject, the theory of money at that time, completely deprived of the basic result of the theory of value, i.e. "that the relative value of two commodities depends upon their relative marginal utility": "to an ingénu, who comes over to monetary theory - he wrote - it is extremely trying to be deprived of this sheet-anchor. It was marginal utility that really made sense of the theory of value [...] What is wanted is a "marginal revolution" ".

The same feeling could be perceived by a non-financial economist trying to deal with the theory of asset prices and, more generally, the value of uncertain prospects.

At its very beginnings, in the XVII century, the value of an uncertain prospect (i.e. a random variable in modern language) was defined by its expected value or just 'value'. Christian Huygens' (1657) book represented, just after the years of the Pascal-Fermat correspondence, a milestone in the theoretical development: "he was trying to justify a method for pricing gambles which happens to be the same as what we call mathematical expectation" (Hacking, 1975, p. 95).

A few decades later, the expectation as a valuation method was greatly undermined by the St. Petersburg paradox, in which a coin-tossing game produces an infinite expectation even if none would pay an infinite amount to play such a game.

The name of the paradox is due to the solution, proposed by Daniel Bernoulli (1738) to a question posed by his cousin Nicolas Bernoulli.

In the words of Nicolas (dated September, $9^{\text {th }}, 1713$ and reported in Bernoulli, 1738), the St. Petersburg's game (or martingale strategy) is as follows; "Peter tosses a coin and continues to do so until it should land "heads" when it comes to the ground. He agrees to give Paul one ducat if he gets "heads" on the very first throw, two ducats if he gets it on the second, four if on the third, eight if on the fourth, and so on, so that with each additional throw the number of ducats he must pay is doubled".

Paul is the player: if he obtain head at the first flip he wins 1 , at the second flip he wins $2, \ldots$, at the $n$-th flip he wins $2^{\text {n- } 1}$ and so on. The question is to seek the fair price G to enter (or sell) the game.

Clearly, the price must be at least 1 (the minimum gain) but the expected gain is infinite:

\begin{tabular}{|c|c|c|}
\hline Flip & Probability & Prize \\
\hline 1 & $1 / 2$ & 1 \\
\hline 2 & $1 / 4$ & 2 \\
\hline$\ldots$. & $\ldots .$. & $\ldots \ldots$ \\
\hline $\mathrm{n}$ & $1 / 2^{\mathrm{n}}$ & $2^{\mathrm{n}-1}$ \\
\hline$\ldots$. & $\ldots \ldots$ & $\ldots \ldots$ \\
\hline
\end{tabular}

$$
\sum_{n=1}^{\infty} 2^{n-1} \frac{1}{2^{n}}=+\infty
$$

However, as Nicolas Bernoulli observed in stating the paradox, nobody would pay an arbitrary large amount to play the game: "it has, he said, to be admitted that any fairly reasonable man would sell his chance, with great pleasure, for twenty ducats" (Bernoulli, 1738, p.32).

The Cramer-Bernoulli solution ${ }^{1}$ provided a path-breaking device, introducing the concept of utility (moral expectation) and reducing the expectation to a finite value:

$\mathrm{G}=\sum_{\mathrm{n}=1}^{\infty} \mathrm{U}\left(2^{\mathrm{n}-1}\right) \frac{1}{2^{\mathrm{n}}}<+\infty$

\footnotetext{
${ }^{1}$ Daniel Bernoulli's solution, in terms of log-utility, was presented to the St. Petersburg Academy of Sciences in 1730 1731 and published in 1738. A similar solution, in terms of square-root utility, was independently proposed to Nicolas Bernoulli by Gabriel Cramer in a letter dated 1728.
} 
It had two relevant consequences: firstly, probability instead of expectation became the primitive concept of any theory of uncertainty, from Laplace (1795) to Kolmogorov (1933); secondly, the expected-utility approach became the fundamental framework for any valuation and decision theory.

With respect to both consequences, it can be pointed out that the route undertaken by the theoretical mainstream in the world was not the only possible one.

With respect to the first consequence, the mathematical theory of uncertainty could be obtained by starting from an axiomatic definition of expectation. ${ }^{2}$

With respect to the second consequence, a simpler solution would be to introduce, instead of the utility of money, additional moments of order greater than one as representative of different dimensions or characteristics of the uncertain prospects.

This was the attempt made by Hicks $(1962,1967 \mathrm{a})$, in his pure theory of portfolio selection.

Having discarded expectation and expected utility, "the third alternative is to look at the regular statistical parameters of the prospect, considered as a probability distribution - not just the first moment (E) but other moments also" (ivi, p. 106).

In the following, we shall consider this Hicksian line of reasoning, showing that it can greatly simplify the theory of asset prices. Our hope is to have gone a bit further, in the sense of recognizing that when a probability distribution is expressed by an appropriate number of parameters, these parameters represent quantities of joint products directly priced by the market.

\section{The simplest approach to asset prices: "measurement without theory"}

What appends to a world where only risk-free assets exist is well known (and uninteresting). Let us suppose, therefore, that there is a single risky asset, along with an endogenous risk-free bond ${ }^{3}$ maturing at the investment horizon $\mathrm{T}$. Clearly, the risky asset is the market portfolio.

We assume that only two characteristics (moments) exist, mean and standard deviation, $\mu_{0}$ and $\sigma_{0}=0$ for the risk free asset and $\mu_{\mathrm{M}}$ and $\sigma_{\mathrm{M}}$ for the market portfolio.

These two parameters may be conceived in general as two "joint products" accruing to the owner. Similarly to all products traded on the market these two joint products have their own market prices: the price of expected money (for example the price of one euro that we expect next year) and the price of risk (loosely speaking, the risk of obtaining from minus to plus one euro in addition to expected money). Note that saying this is not quite as saying that that these parameters represent the result of expected utility maximisation, as it is usually done. We stress the fact that these two parameters are much like goods and services: they may be measured, have their own market price and are to be thought of as arguments of an ordinal utility function.

Let us use the symbols $\mathrm{P}_{\mu}$ and $\mathrm{P}_{\sigma}$ to indicate, respectively, the unit market price of expected money (the first characteristic) and the unit market price of risk (second characteristic or expected deviation, volatility, standard deviation or any other name you are willing to use). People like expected money, but are generally risk averse. They would be happy if it were possible to preserve the money expected from their asset and do without its risk. But that risk is part of the asset: its market price wouldn't be the same if that risk were not there ${ }^{4}$.

The price of the market portfolio can be written as:

$\mathrm{P}_{\mathrm{M}}=\mu_{\mathrm{M}} \mathrm{P}_{\mu}+\sigma_{\mathrm{M}} \mathrm{P}_{\sigma}$

where $\mathrm{P}_{\mu}$ is the market price of one unit of the first characteristic (expected value) and $\mathrm{P}_{\sigma}$ is the price of the second characteristic.

\footnotetext{
2 For such an alternative approach, going from expectation to probability instead of vicevesa, see Whittle (1992). He recognizes the similarity with de Finetti (1970) and Savage (1972) subjectivist approach. In fact, the former obtains probability from expectation ('prevision'), the latter from primitive preferences over acts. A game-theory approach to probability, rooted back into the Pascal and Huygens pricing methods, has been recently proposed by Shafer and Vovk (2001).

${ }^{3}$ Endogenous means that its aggregated demand is zero.

${ }^{4}$ A not too different situation is the one of a production process from which both a desired product and pollution are obtained.
} 
Such a formula has the same value for a theory of asset prices as the bill in a restaurant has for a theory of commodity prices: it simply says that the total value is the sum of prices times quantities of each single component.

The risk free asset is no exception:

$\mathrm{P}_{0}=\mu_{0} \mathrm{P}_{\mu}$

and if the expected value is just one unit of money, $\mu_{0}=1$, then we can identify the market price of the mean with the price of the unit zero-coupon bond:

$\mathrm{P}_{0}=\mathrm{P}_{\mu}$

Therefore:

$\mathrm{P}_{\mathrm{M}}=\mu_{\mathrm{M}} \mathrm{P}_{0}+\sigma_{\mathrm{M}} \mathrm{P}_{\sigma}$

saying that the price $\mathrm{P}_{M}$ is the discounted expected value, $\mu_{M} \mathrm{P}_{0}$, plus an adjustment, , $\sigma_{M} \mathrm{P}_{\sigma}$, proportional to its risk.

Note that if the price $\mathrm{P}_{\mathrm{M}}$ and its moments are observable and the market reflects equilibrium values, then we can obtain:

$P_{\sigma}=\frac{P_{M}-\mu_{M} P_{0}}{\sigma_{M}}$

Risk aversion means that $\mathrm{P}_{\sigma}$ is negative, i.e. that the market portfolio has a price less than its discounted expected value. For example:

$P_{\sigma}=\frac{1-1.1 \cdot 0.97}{0.50}=-0.134$

Let us suppose, now, that the market portfolio is a linear combination of $\mathrm{n}$ different risky assets.

The price of any single risky asset $\mathrm{P}_{\mathrm{j}}$ with outstanding quantity $\mathrm{x}_{\mathrm{j}}$, is simply obtained from (2.4) as:

$\mathrm{P}_{\mathrm{j}}=\frac{\partial \mathrm{P}_{\mathrm{M}}}{\partial \mathrm{x}_{\mathrm{j}}}=\mu_{\mathrm{j}} \mathrm{P}_{0}+\frac{\partial \sigma_{\mathrm{M}}}{\partial \mathrm{x}_{\mathrm{j}}} \mathrm{P}_{\sigma}$

with:

$\frac{\partial \sigma_{M}}{\partial x_{j}}=\frac{\sum_{k=1}^{n} x_{k} \sigma_{j k}}{\sigma_{M}}=\frac{\operatorname{Cov}\left(\widetilde{P}_{j}, \sum_{k=1}^{n} x_{k} \widetilde{P}_{k}\right)}{\sigma_{M}}=\frac{\operatorname{Cov}\left(\widetilde{P}_{j}, \widetilde{P}_{M}\right)}{\sigma_{M}}=\frac{E\left[\left(\widetilde{P}_{M}-\mu_{M}\right)\left(\widetilde{P}_{j}-\mu_{j}\right)\right]}{\sigma_{M}}$

so that, using (2.5):

$P_{j}=\mu_{j} P_{0}+\frac{\operatorname{Cov}\left(\widetilde{P}_{j}, \widetilde{P}_{M}\right)}{\sigma_{M}^{2}}\left(P_{M}-\mu_{M} P_{0}\right)$

which is clearly the CAPM of Sharpe (1964) in price terms.

In fact, dividing both sides by $\mathrm{P}_{0}$ and by $\mathrm{P}_{\mathrm{j}}$ and rearranging:

$\frac{\mu_{j}}{P_{j}}=\frac{1}{P_{0}}-\frac{P_{M}^{2} \operatorname{Cov}\left(\frac{\widetilde{P}_{j}}{P_{j}}, \frac{\widetilde{P}_{M}}{P_{M}}\right)}{\sigma_{M}^{2}}\left(\frac{1}{P_{0}}-\frac{\mu_{M}}{P_{M}}\right)$

i.e. 
$\overline{\mathrm{R}}_{\mathrm{j}}=\mathrm{R}_{\mathrm{F}}+\frac{\operatorname{Cov}\left(\widetilde{\mathrm{R}}_{\mathrm{j}}, \widetilde{\mathrm{R}}_{\mathrm{M}}\right)}{\sigma_{\mathrm{RM}}^{2}}\left(\overline{\mathrm{R}}_{\mathrm{M}}-\mathrm{R}_{\mathrm{F}}\right)$

\section{Theoretical foundations}

It is well known that the theory of choice under uncertainty maps decisions into probability distributions, so that preferences and ordinal utility $\mathrm{V}$ are defined over the set $\mathfrak{I}$ of distribution functions:

$\mathrm{V}: \mathrm{F} \in \mathfrak{I} \longrightarrow \mathrm{R}$

Instead of introducing the highly questionable 'independence axiom' and its related expected utility theorem ${ }^{5}$, let us represent a probability distribution through its moments, so that, in general ${ }^{6}$ :

$\mathrm{V}(\mathrm{F})=\mathrm{H}(\mu, \sigma, \zeta, \kappa, \ldots)$

This implies that any asset, like any consumption good in Lancaster's (1966) theory, is a bundle of characteristics (moments) with significant pricing implications.

In the case of a single risky asset we have, for the representative investor with current wealth $\mathrm{W}$ :

$$
\left\{\begin{array}{l}
\max _{\mathrm{x}_{0}, \mathrm{x}_{\mathrm{M}}} \mathrm{H}(\mu, \sigma) \\
\mu=\mathrm{x}_{0} \mu_{0}+\mathrm{x}_{\mathrm{M}} \mu_{\mathrm{M}} \\
\sigma=\mathrm{x}_{\mathrm{M}} \sigma_{\mathrm{M}} \\
\mathrm{W}=\mathrm{x}_{0} \mathrm{P}_{0}+\mathrm{x}_{\mathrm{M}} \mathrm{P}_{\mathrm{M}}
\end{array}\right.
$$

The first-order conditions (FOC) are:

$$
\begin{aligned}
& \frac{\partial \mathrm{H}}{\partial \mu} \mu_{0}-\lambda \mathrm{P}_{0}=0 \\
& \frac{\partial \mathrm{H}}{\partial \mu} \mu_{\mathrm{M}}+\frac{\partial \mathrm{H}}{\partial \sigma} \sigma_{\mathrm{M}}-\lambda \mathrm{P}_{\mathrm{M}}=0
\end{aligned}
$$

so that, assuming without loss of generality $\mu_{0}=1$, we have:

$$
\frac{\mathrm{P}_{\mathrm{M}}}{\mathrm{P}_{0}}=\mu_{\mathrm{M}}+\frac{\partial \mathrm{H} / \partial \sigma}{\partial \mathrm{H} / \partial \mu} \sigma_{\mathrm{M}}
$$

In terms of characteristics, current wealth $\mathrm{W}$ can be equivalently expressed as:

$\mathrm{W}=\mu \mathrm{P}_{\mu}+\sigma \mathrm{P}_{\sigma}$

so that, from the FOC,

$$
\frac{\partial \mathrm{H} / \partial \sigma}{\partial \mathrm{H} / \partial \mu}=\frac{\mathrm{P}_{\sigma}}{\mathrm{P}_{\mu}}
$$

and substituting:

\footnotetext{
${ }^{5}$ For a review of the expected utility theory and its alternatives see Machina (1987).

${ }^{6}$ It is always possible to pass from distributions to moments. The viceversa, so called problem of moments, is not always guaranteed over infinite range. For a discussion, see Kendall and Stuart (1977) ch.4.
} 
$\mathrm{P}_{\mathrm{M}}=\mu_{\mathrm{M}} \mathrm{P}_{0}+\frac{\mathrm{P}_{\sigma}}{\mathrm{P}_{\mu}} \mathrm{P}_{0} \sigma_{\mathrm{M}}=\mu_{\mathrm{M}} \mathrm{P}_{0}+\sigma_{\mathrm{M}} \mathrm{P}_{\sigma}$

the last equality coming from $\mathrm{P}_{0}=\mu_{0} \mathrm{P}_{\mu}=\mathrm{P}_{\mu}$.

In the case of $\mathrm{n}$ risky assets, the problem becomes:

$$
\left\{\begin{array}{l}
\max _{\mathrm{x}_{0}, \mathrm{x}_{1}, \ldots \ldots \mathrm{x}_{\mathrm{k}}, \ldots \mathrm{x}_{\mathrm{n}}} \mathrm{H}(\mu, \sigma) \\
\mu=\mathrm{x}_{0} \mu_{0}+\sum_{\mathrm{k}=1}^{\mathrm{n}} \mathrm{x}_{\mathrm{k}} \mu_{\mathrm{k}} \\
\sigma=\sqrt{\sum_{\mathrm{h}=1}^{\mathrm{n}} \sum_{\mathrm{k}=1}^{\mathrm{n}} \mathrm{x}_{\mathrm{h}} \mathrm{x}_{\mathrm{k}} \sigma_{\mathrm{hk}}} \\
\mathrm{W}=\mathrm{x}_{0} \mathrm{P}_{0}+\sum_{\mathrm{k}=1}^{\mathrm{n}} \mathrm{x}_{\mathrm{k}} \mathrm{P}_{\mathrm{k}}
\end{array}\right.
$$

with FOC:

$$
\begin{aligned}
& \frac{\partial \mathrm{H}}{\partial \mu} \mu_{0}-\lambda \mathrm{P}_{0}=0 \\
& \frac{\partial \mathrm{H}}{\partial \mu} \mu_{\mathrm{j}}+\frac{\partial \mathrm{H}}{\partial \sigma} \frac{\sum_{\mathrm{k}=1}^{\mathrm{n}} \mathrm{x}_{\mathrm{k}} \sigma_{\mathrm{jk}}}{\sigma}-\lambda \mathrm{P}_{\mathrm{j}}=0
\end{aligned}
$$

so that, using $\mathrm{P}_{0}=\mathrm{P}_{\mu}$ :

$\mathrm{P}_{\mathrm{j}}=\mu_{\mathrm{j}} \mathrm{P}_{0}+\frac{\sum_{\mathrm{k}=1}^{\mathrm{n}} \mathrm{x}_{\mathrm{k}} \sigma_{\mathrm{jk}}}{\sigma} \mathrm{P}_{\sigma}=\mu_{\mathrm{j}} \mathrm{P}_{0}+\frac{\operatorname{Cov}\left(\widetilde{\mathrm{P}}_{\mathrm{j}}, \sum_{\mathrm{k}=1}^{\mathrm{n}} \mathrm{x}_{\mathrm{k}} \widetilde{\mathrm{P}}_{\mathrm{k}}\right)}{\sigma} \mathrm{P}_{\sigma}$

In equilibrium, $\mathrm{x}_{0}=0$ and $\sigma=\sigma_{\mathrm{M}}$ (the market portfolio volatility) so that (3.9) is equivalent to (2.6), i.e. CAPM: it says that the equilibrium asset price is the expected value $\mu_{\mathrm{j}}$ discounted and adjusted by a risk measure proportional to the covariance between the asset price and the market portfolio.

Note that a risky asset having market price $\mathrm{P}_{\sigma}$ may occasionally exist in the real world as an asset with zero expected value.

For example, in the case of a 'synthetic forward' contract (a long call and a short put position) written on an asset $\mathrm{P}_{\mathrm{j}}$ with strike price equal to the expected value $\mu_{\mathrm{j}}$, the price formula gives:

$$
\mathrm{P}_{\mathrm{FW}}=\mathrm{P}_{\sigma} \frac{\operatorname{Cov}\left(\widetilde{\mathrm{P}}_{\mathrm{M}}, \widetilde{\mathrm{P}}_{\mathrm{j}}\right)}{\sigma_{\mathrm{M}}}
$$

If the asset is the market portfolio itself, we have simply that the price of the contract is $P_{\sigma}$ times $\sigma_{M}$, a negative quantity. ${ }^{7}$

Elsewhere (Cesari and D'Adda, 2003) we have shown that the simple pricing procedure suggested above may be successfully applied to options, allowing to reproduce the Black and Scholes equation and its possible generalizations.

${ }^{7}$ Note that in this case the strike is $\mu_{M}=\frac{\mathrm{P}_{M}-\mathrm{P}_{\sigma} \sigma_{M}}{\mathrm{P}_{0}}$, greater than the forward price $\frac{\mathrm{P}_{M}}{\mathrm{P}_{0}}$ for which the contract has zero value. 


\section{Extensions to higher moments}

If higher moments exist, beyond mean and standard deviation, the reasoning goes through as before.

The price of the market portfolio has the simple bill-shape:

$\mathrm{P}_{\mathrm{M}}=\mu_{\mathrm{M}} \mathrm{P}_{\mu}+\sigma_{\mathrm{M}} \mathrm{P}_{\sigma}+\varsigma_{\mathrm{M}} \mathrm{P}_{\varsigma}+\kappa_{\mathrm{M}} \mathrm{P} \kappa+\ldots \ldots$

$\varsigma_{M}, \kappa_{M}$ etc. being, respectively, skewness, kurtosis and higher moments of the market portfolio:

$$
\begin{aligned}
& \varsigma_{M}=\left[E\left(\widetilde{P}_{M}-\mu_{M}\right)^{3}\right]^{\frac{1}{3}} \\
& \kappa_{M}=\left[E\left(\widetilde{P}_{M}-\mu_{M}\right)^{4}\right]^{\frac{1}{4}}
\end{aligned}
$$

and the generic asset $\mathrm{j}$ has price:

$\mathrm{P}_{\mathrm{j}}=\frac{\partial \mathrm{P}_{\mathrm{M}}}{\partial \mathrm{x}_{\mathrm{j}}}=\mu_{\mathrm{j}} \mathrm{P}_{0}+\frac{\partial \sigma_{\mathrm{M}}}{\partial \mathrm{x}_{\mathrm{j}}} \mathrm{P}_{\sigma}+\frac{\partial \varsigma_{\mathrm{M}}}{\partial \mathrm{x}_{\mathrm{j}}} \mathrm{P}_{\zeta}+\frac{\partial \kappa_{\mathrm{M}}}{\partial \mathrm{x}_{\mathrm{j}}} \mathrm{P}_{\mathrm{\kappa}}+\ldots \ldots$

where, in addition to the covariance term, a co-skewness and a co-kurtosis of the asset with the market portfolio are included:

$$
\begin{aligned}
& \frac{\partial \sigma_{M}}{\partial x_{j}}=\frac{E\left[\left(\widetilde{P}_{M}-\mu_{M}\right)\left(\widetilde{P}_{j}-\mu_{j}\right)\right]}{\sigma_{M}} \\
& \frac{\partial \varsigma_{M}}{\partial x_{j}}=\frac{E\left[\left(\widetilde{P}_{M}-\mu_{M}\right)^{2}\left(\widetilde{P}_{j}-\mu_{j}\right)\right]}{\varsigma_{M}^{2}} \\
& \frac{\partial \kappa_{M}}{\partial x_{j}}=\frac{E\left[\left(\widetilde{P}_{M}-\mu_{M}\right)^{3}\left(\widetilde{P}_{j}-\mu_{j}\right)\right]}{\kappa_{M}^{3}}
\end{aligned}
$$

Is this a " theory" of asset pricing?

According to a common point of view in Finance, the CAPM is a theory of asset pricing based on the maximisation of expected utility of future wealth. We have solved a simpler problem, by applying the observed market price of unit future expected money and the market price of unit of risk to the amount of future money and risk born by an asset and we have obtained the CAPM. If it were possible, we would expect that John Hicks would consent to the procedure we have followed. Viewed in these terms CAPM appears as a "theory" of assets prices no more than the bill handed over to us before living a supermarket represents a theory of prices of consumer's goods.

Of course we can interpret the observed price of the market portfolio as the ultimate result of agents' expected utility maximisation, supplemented by the execution of all possible arbitrages. Consequently you may continue interpreting the CAPM as a theory based on expected utility maximisation, provided that you are willing to afford all critiques addressed to expected utility. 


\section{Solving the St. Petersburg and Allais paradoxes}

The St. Petersburg paradox. In the introduction, we have recalled the St. Petersburg's game and Daniel Bernoulli's solution in terms of expected utility ${ }^{8}$ :

\begin{tabular}{|c|c|c|}
\hline Flip & Probability & Prize \\
\hline 1 & $1 / 2$ & 1 \\
\hline 2 & $1 / 4$ & 2 \\
\hline$\ldots$. & $\ldots$. & $\ldots \ldots$ \\
\hline $\mathrm{n}$ & $1 / 2^{\mathrm{n}}$ & $2^{\mathrm{n}-1}$ \\
\hline$\ldots$. & $\ldots \ldots$ & $\ldots \ldots$ \\
\hline
\end{tabular}

$\mathrm{G}=\sum_{\mathrm{n}=1}^{\infty} \mathrm{U}\left(2^{\mathrm{n}-1}\right) \frac{1}{2^{\mathrm{n}}}<+\infty$

Alternatively, the price of the game can be obtained in our approach by considering the game as a portfolio of subgames (one for each row in the table above) the first of which implies a prize of 1 if we get head at the first flip and 0 otherwise, the second of which implies a prize of 2 if we get head at the second flip and 0 otherwise, the n-th of which implies a prize of $2^{\text {n-1 }}$ if we get head at the n-th flip and zero otherwise.

For each game $n$, the expected value is always $1 / 2$ and the standard deviation is $0.5\left(2^{n}-1\right)^{0.5}$ :

$$
\begin{aligned}
& \text { mean }=2^{\mathrm{n}-1} \frac{1}{2^{\mathrm{n}}}+0\left(1-\frac{1}{2^{\mathrm{n}}}\right)=\frac{1}{2} \\
& \text { var iance }=\left(2^{\mathrm{n}-1}-\frac{1}{2^{2}}\right)^{2} \frac{1}{2^{\mathrm{n}}}+\left(0-\frac{1}{2}\right)^{2}\left(1-\frac{1}{2^{\mathrm{n}}}\right)=\frac{2^{\mathrm{n}}-1}{4}
\end{aligned}
$$

\begin{tabular}{|c|c|c|c|c|}
\hline Subgame & Probability & Prize & $\begin{array}{c}\text { Expected } \\
\text { Prize }\end{array}$ & $\begin{array}{c}\text { Standard } \\
\text { Deviation }\end{array}$ \\
\hline 1 & $1 / 2$ & 1 & $1 / 2$ & 0.50 \\
\hline 2 & $1 / 4$ & 2 & $1 / 2$ & 0.87 \\
\hline$\ldots$. & $\ldots$. & $\ldots \ldots$ & $\ldots \ldots$ & $\ldots$. \\
\hline $\mathrm{n}$ & $1 / 2^{\mathrm{n}}$ & $2^{\mathrm{n}-1}$ & $1 / 2$ & $0.5^{*}\left(2^{\mathrm{n}}-1\right)^{0.5}$ \\
\hline$\ldots$. & $\ldots \ldots$ & $\ldots \ldots$ & $\ldots \ldots$ & $\ldots$. \\
\hline
\end{tabular}

Considering the first two moments and assuming for simplicity the standard deviation as a proxy for the risk, the price of the n-th subgame is:

$\mathrm{G}_{\mathrm{n}}=\left\{\begin{array}{cc}\frac{1}{2} \mathrm{P}_{0}+\frac{\sqrt{2^{\mathrm{n}}-1}}{2} \mathrm{P}_{\sigma} \text { if positive i.e. if } & \mathrm{n}<\mathrm{n}^{\circ} \equiv \frac{\ln \left(1+\left(\frac{\mathrm{P}_{0}}{\mathrm{P}_{\sigma}}\right)^{2}\right)}{\ln 2} \\ 0 & \text { otherwise }\end{array}\right.$

\footnotetext{
${ }^{8}$ Note that Bernoulli's solution has limited validity because, given $\mathrm{U}$, it may be possible to find a lottery with prize $\mathrm{w}_{\mathrm{n}}$ such that $U\left(w_{n}\right)=2^{n-1}$, i.e. $w_{n}=U^{-1}\left(2^{n-1}\right)$, so that the expected utility is infinite. This is the so called Karl Menger's superparadox (1934), implying a limited $U$ for the expectation to be finite. A different solution is provided by Whittle (1992, p. 65) using a discount factor.
} 
where the limited liability provision has been applied and the price of the game is just the sum of the (positive) prices of all subgames:

$\mathrm{G}=\sum_{\mathrm{n}=1}^{\infty} \mathrm{G}_{\mathrm{n}}=\sum_{\mathrm{n}=1}^{\infty} \max \left(\frac{\mathrm{P}_{0}}{2}+\frac{\mathrm{P}_{\sigma}}{2} \sqrt{2^{\mathrm{n}}-1}, 0\right)$

For example, if $P_{0}=1$ and $P_{\sigma}=-0.134$ then $n^{\circ}=5.8$ and $G=1.507$. This means that coin tosses beyond the fifth have no economic value ${ }^{9}$.

The Allais paradox. The Allais (1953) paradox is a factual evidence against expected utility.

In fact, asking people to choose between games A and B, where A gives 1 million with certainty $\left(\mathrm{p}_{2}=100 \%\right)$ and $\mathrm{B}$ gives 1 million with only $89 \%$ probability and 0 or 5 millions with the remaining chances $\left(p_{1}=1 \%, p_{3}=10 \%\right)$ :

$A=\left\{\begin{array}{ll}1 & 100 \%\end{array} \quad \mathrm{~B}=\left\{\begin{array}{cc}0 & 1 \% \\ 1 & 89 \% \\ 5 & 10 \%\end{array}\right.\right.$

people prefer in large majority $\mathrm{A}$ to $\mathrm{B}: \mathrm{A} \succ \mathrm{B}$

Then, asking them to choose between $A^{\prime}$ and B' defined by:

$\mathrm{A}^{\prime}=\left\{\begin{array}{cc}0 & 89 \% \\ 1 & 11 \%\end{array} \quad \mathrm{~B}^{\prime}= \begin{cases}0 & 90 \% \\ 5 & 10 \%\end{cases}\right.$

the same people very often prefer B' to $A^{\prime}: B^{\prime} \succ A^{\prime}$.

The paradox stems from the fact that from $\mathrm{A} \succ \mathrm{B}$, the expected utility approach deduces $\mathrm{A}^{\prime} \succ \mathrm{B}^{\prime}$, which is at variance with the experimental evidence (Allais reports $53 \%$ of cases of violation of the logical implication).

In fact, $\mathrm{A} \succ \mathrm{B}$ means $\mathrm{U}(1)>0.01 \mathrm{U}(0)+0.89 \mathrm{U}(1)+0.10 \mathrm{U}(5)$ but collecting $\mathrm{U}(1)$ and adding to both members of the inequality $0.89 \mathrm{U}(0)$ you obtain, algebrically:

$0.89 \mathrm{U}(0)+0.11 \mathrm{U}(1)>0.9 \mathrm{U}(0)+0.10 \mathrm{U}(5)$ i.e. $\mathrm{A}^{\prime} \succ \mathrm{B}^{\prime}$, againts the empirical evidence.

According to Allais, either people in experimental situations do not use the rational thinking used in real world decision making ${ }^{10}$ or people do not follow the expected utility paradigm.

In fact, using our approach, the rationality of the choices actually made in the experiment may be easily recognized.

Considering each lottery as an asset, the first four moments are:

\begin{tabular}{|l|c|c|c|c|}
\hline & $\mathbf{A}$ & $\mathbf{B}$ & $\mathbf{A}$ & $\mathbf{B}^{\prime}$ \\
\hline mean, $\boldsymbol{\mu}$ & 1.000 & 1.390 & 0.110 & 0.500 \\
\hline standard deviation, $\boldsymbol{\sigma}$ & 0 & 1.207 & 0.313 & 1.500 \\
\hline skewness, $\boldsymbol{\varsigma}$ & 0 & 1.666 & 0.424 & 2.080 \\
\hline kurtosis, $\boldsymbol{\kappa}$ & 0 & 2.032 & 0.513 & 2.531 \\
\hline
\end{tabular}

Assuming the following prices of the four moments:

$\mathrm{P}_{0}=1, \mathrm{P}_{\sigma}=-0.34, \mathrm{P}_{\varsigma}=0.01, \mathrm{P}_{\mathrm{K}}=-0.001$ we obtain the prices of the lotteries: $\mathrm{P}(\mathrm{A})=1>\mathrm{P}(\mathrm{B})=0.994$ and $\mathrm{P}\left(\mathrm{A}^{\prime}\right)=0.007<$ $\mathrm{P}\left(\mathrm{B}^{\prime}\right)=0.008$, in accordance with the Allais experiments.

This means that, using the Marschak triangle as in Machina (1987), the indifference curves in our approach are nonlinear in the probabilities and may display a 'fanning out' effect from the sure event A as implied in actual behavior.

\footnotetext{
9 A greater price $G$ could be obtained using also higher moments: the skewness of the $n$-th subgame is $\left[0.25\left(2^{n}-1\right)\left(2^{n-1}-\right.\right.$ $1)]^{1 / 3}$; the kurtosis is $\left[\left(2^{\mathrm{n}}-1\right)\left(\left(2^{\mathrm{n}}-1\right)^{3}+1\right) / 2^{\mathrm{n}+4}\right]^{1 / 4}$.

${ }^{10}$ Savage (1972, ch.5) himself made the 'error' when asked to make his choices.
} 


\section{References}

Allais, M. (1953), Le comportement de l'homme rationnel devant le risque. Critique des postulats et axiomes de l'école américaine, Econometrica, 21, pp. 503-546.

Bernoulli, D. (1738), Specimen theoriae novae de mensura sortis, in Commentarii Academiae Scientiarum Imperialis Petropolitanae, Vol. V, for the years 1730-1731, translated by L. Sommer, Exposition of a new theory on the measurement of risk, Econometrica, 22, 1, 1954, pp.23-36

Cesari, R. and D'Adda, C. (2003), A Simple Approach to the Theory of Asset Pricing, Social Sciences Research Network Electronic Library, http://papers.ssrn.com/sol3/papers.cfm?abstract_id=519443

de Finetti, B. (1970), Teoria della probabilità, English translation, Theory of probability, New York, Wiley, 1974

Hacking, I. (1975), The emergence of probability, Cambridge, CUP

Hicks, J.R. (1935), A suggestion for simplifying the theory of money, Economica, February, now in Hicks (1967b), ch. 4.

Hicks, J. R. (1962), Liquidity, Economic Journal, 72, Dec., pp. 787-802

Hicks, J. R. (1967a), The pure theory of portfolio selection, in Hicks (1967b) ch. 6.

Hicks, J. R. (1967b), Critical essays in monetary theory, Oxford, OUP.

Huygens, C. (1657), De ratiociniis in ludo aleae, translated by J. Arbuthnot, Of the laws of chance, or, a method of calculation of the hazards of game, London, 1692.

Kendall, M. and Stuart, A. (1977), The advanced theory of statistics, vol. 1, Distribution theory, London, Griffin \& Co, $4^{\text {th }}$ ed.

Lancaster, K. (1966), A new approach to consumer theory, Journal of Political Economy, 74, pp. 132-157

Machina, M.J. (1987), Choice under uncertainty: problems solved and unsolved, Economic Perspectives, 1,1, pp. 121154

Savage, L. J. (1972), The foundation of statistics, New York, Dover, $2^{\text {nd }}$ edition

Shafer G. and Vovk, V. (2001), Probability and Finance. It’s only a game!, New York, Wiley

Sharpe, W.F. (1964), Capital asset prices: a theory of market equilibrium under conditions of risk", Journal of Finance, 19 , pp. $425-442$

Whittle, P. (1992), Probability via expectation, New York, Springer-Verlag, $3^{\text {rd }}$ edition 